\title{
Discurso Anti-Ciência: a Desinformação como Estratégia de Ataque à Produção Científica
}

\author{
Anti-Science Speech: Disinformation as a Strategy for \\ Attacking Scientific Production
}

\section{Discurso Anticiencia: la Desinformación como Estrategia para Atacar la Producción Científica}

\author{
(iD) Leonardo Luiz de Souza Rezio \\ Universidade Federal de Goiás (UFG), Goiânia, Goiás, Brasil \\ leonardorezio@ufg.br \\ (iD) 9 \\ Magno Luiz Medeiros da Silva \\ Universidade Federal de Goiás (UFG), Goiânia, Goiás, Brasil \\ magno@ufg.br
}

Resumo: O presente artigo tem como objetivo analisar os ataques sofridos nas redes sociais pelo grupo de trabalho de modelagem da COVID-19 da Universidade Federal de Goiás, em decorrência do fechamento das atividades não essenciais de forma intermitente pelo governo do Estado. A partir de uma análise qualitativa, tendo como enfoque o discurso anti-ciência, buscou-se compreender como as fake news e a desinformação levantadas pelos setores que se mostraram contra o fechamento das atividades comerciais, contribuíram para a desqualificação do papel da ciência e para a tentativa de descrédito em relação à função social da universidade pública. Concluiu-se, por meio da análise, que a grade econômica tende a se sobrepor a outros fenômenos da vida social, que não meramente fenômenos econômicos, como no caso, a saúde coletiva. 
Palavras-chave: Anti-ciência. Desinformação. Fake news. COVID-19.

Abstract: This article aims to analyze the attacks suffered on social networks by the modeling workgroup of COVID-19 from the Federal University of Goiás, due to the intermittent closure of non-essential activities by the government of the State. From a qualitative analysis, focusing on anti-science discourse, we sought to understand how fake news and disinformation raised by the sectors that were against the closure of commercial activities, contributed to the disqualification of the role of science and to the attempt to discredit in relation to the social function of the public university. It was concluded, through analysis, that the economic grid tends to overlap with other phenomena of social life, which are not merely economic phenomena, as in this case, collective health.

2

Key Words: Anti-science. Disinformation. Fake news. COVID-19.

Resumen: Este artículo tiene como objetivo analizar los ataques sufridos en redes sociales por el grupo de trabajo de modelado del COVID-19 de la Universidad Federal de Goiás, debido al cierre intermitente de actividades no esenciales por parte del gobierno del Estado. A partir de un análisis cualitativo, enfocándonos en el discurso anti-ciencia, buscamos entender cómo las fake news y la desinformación levantadas por los sectores que se oponían al cierre de actividades comerciales, contribuyeron a la descalificación del rol de la ciencia y al intento de desprestigio en relación con la función social de la universidad pública. Se concluyó, a través del análisis, que el entramado económico tiende a superponerse con otros fenómenos de la vida social, que no son meramente económicos, como en este caso, la salud colectiva. 
Palabras-clave: Anti-ciencia. Desinformación. Fake news. COVID-19.

Data de submissão: 26/10/2020

Data de aprovação: 16/12/2020

3

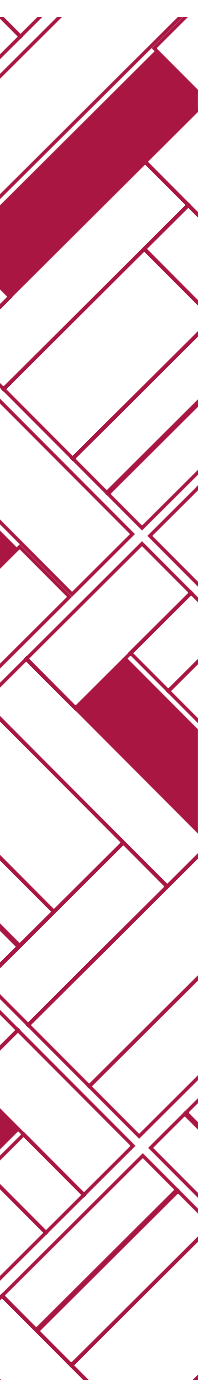


Discurso Anti-Ciência: a Desinformação como Estratégia de Ataque à Produção Científica Leonardo Luiz de Souza Rezio • Magno Luiz Medeiros da Silva

\section{Introdução}

No contexto da pandemia de COVID-19 em Goiás, logo após a decretação de situação de emergência na saúde pública do Estado, em 13 de março de 2020, foi formado na Universidade Federal de Goiás (UFG) o grupo de trabalho de modelagem da COVID-19. O objetivo do grupo seria o de fornecer evidências e previsões a partir de cenários futuros de expansão que pudessem subsidiar políticas públicas. O grupo é composto por três professores da casa, a médica epidemiologista Cristiana Toscano e os biólogos da área de Ecologia e Evolução, José Alexandre Felizola Diniz Filho e Thiago Rangel. Uma equipe interdisciplinar e com experiência em bioestatística, modelagem computacional e epidemiologia, reconhecidos por seus trabalhos em âmbito nacional e internacional.

Se valendo de métodos matemáticos e computacionais, o projeto de modelagem epidemiológica desenvolvido pelo grupo, denominado modelo ABM-COVID-GO-III, permitiu avaliar a expansão da COVID-19 e os impactos estimados no sistema de saúde no Estado de Goiás. Para tanto, foram considerados diferentes cenários futuros de transmissibilidade, resultantes das medidas de distanciamento social implementadas e o comportamento da população ao longo do tempo. Com o modelo foi possível, ainda, estimar a demanda de leitos hospitalares convencionais e leitos de UTI para pacientes com COVID-19, por macrorregião do Estado e, a partir de cenários, estimar o número de óbitos por COVID-19 acumulados ao longo do tempo, para o Estado como um todo e por macrorregião (MELO e STECCA, 2020).

Os resultados das estimativas apresentadas em notas técnicas, bem como a estrutura e metodologia dos modelos desenvolvidos, foram apresentados, discutidas e validadas pelo Comitê de 
Discurso Anti-Ciência: a Desinformação como Estratégia de Ataque à Produção Científica Leonardo Luiz de Souza Rezio • Magno Luiz Medeiros da Silva

Operações de Emergência em Saúde Pública do Estado de Goiás (COE-COVID-19).

Com as atualizações das projeções apresentadas logo nas primeiras versões do modelo, houve um respaldo científico para a conscientização da população acerca do isolamento social, com bons resultados, no início da pandemia em Goiás. Com isso, o governo do Estado pode se preparar melhor para atender os acometidos pela COVID-19.

Entretanto, o isolamento social necessário para se conter a velocidade de transmissão do vírus diminuía gradativamente ao longo do tempo. A partir deste fato, um novo estudo projetou outros cenários possíveis a partir de dados da época, sendo que, em um dos cenários possíveis, o cenário vermelho, aventou-se um provável colapso hospitalar no Estado a partir do mês de julho, e que poderia haver até 18 mil mortes por COVID-19 em Goiás, até setembro de 2020, caso o isolamento social continuasse em $36,89 \%$. Esses dados foram divulgados pelo grupo em live realizada com o Governador do Estado em 29 de junho de 2020 (RODRIGUES, 2020).

Com base nestas projeções trazidas pelo grupo de trabalho, o governador Ronaldo Caiado decidiu, por decreto, pelo fechamento de atividades não essenciais de forma intermitente, intercalando períodos de 14 dias de fechamento e abertura, a partir do dia 30 de junho de 2020. Esperava-se, com isso, que o valor do isolamento social subisse acima de 50 a 60\% para, assim se conseguir "achatar a curva", ou seja, reduzir o número médio de transmissão (R).

Esta medida foi duramente criticada por setores que não concordaram com o isolamento, os quais passaram a fazer pressões para a liberação do comércio, sob o argumento de que se estaria prejudicando a economia do Estado. Todavia, não ficaram apenas 
Discurso Anti-Ciência: a Desinformação como Estratégia de Ataque à Produção Científica Leonardo Luiz de Souza Rezio • Magno Luiz Medeiros da Silva

nas críticas, houve ataques em redes sociais endereçadas aos pesquisadores do Grupo de Modelagem da Expansão da COVID-19 e à própria UFG. Tanto os pesquisadores, quanto à UFG foram acusados de terem oferecidos dados incorretos ao governador e, por isso, terem sido os verdadeiros responsáveis pelo fechamento do comércio em Goiás (LONGO, 2020).

Este artigo pretende, justamente, fazer uma análise qualitativa baseado neste estudo de caso para se tentar compreender, de forma contextualizada, como as críticas e ataques aos pesquisadores e à UFG, difundidos em sites e redes sociais na internet, contribuíram para a desqualificação da ciência e o descrédito em relação à universidade pública junto à sociedade, utilizando-se, para isso, de estratégias de desinformação e fake news. O artigo também pretende analisar como a crença de que é preciso escolher entre "salvar vidas" ou "preservar a economia" tem raízes numa exacerbada economização da vida. É a grade econômica que, no neoliberalismo, se sobrepõe a outros fenômenos da vida social.

O artigo, primeiramente, traz uma abordagem teórica, para se conceituar temas importantes para essa análise, como a questão dos ataques à ciência e à universidade, em especial a universidade pública, a desinformação e as fake news, o fenômeno da dissonância cognitiva e o poder econômico que se sobressai sobre o poder político. Para tanto, os autores mais citados são Stanley (2020), Empoli (2020), Festinger (1975) e Foucault (2008). Outros autores atuais também foram citados em apoio a tais conceitos, como Laval (2019), Martins (2020), Barbosa (2019) e Danner (2009).

A seguir, o artigo irá trazer o relato descritivo das notícias, imagens e vídeos que circularam pelas redes sociais, em especial o Whatsapp, com as mensagens de desqualificação da pesquisa e de descrédito em relação aos próprios pesquisadores e à UFG, apon- 
Discurso Anti-Ciência: a Desinformação como Estratégia de Ataque à Produção Científica Leonardo Luiz de Souza Rezio • Magno Luiz Medeiros da Silva

tados como responsáveis pelo fechamento do comércio. Logo em seguida, iremos verificar se tais argumentos têm procedência verídica ou não, a partir do momento em que se descreve os critérios da pesquisa, o que significam os cenários e a própria característica de incerteza das ciências, segundo relatos dos próprios pesquisadores.

Por fim, o artigo pretende apresentar inferências de acordo com a bibliografia discutida, e, assim, contribuir para a discussão a respeito do discurso anti-ciência nas redes sociais na internet, tendo como análise o caso em estudo. Ressaltamos, todavia que essa discussão irá se exaurir nesse artigo, pois essa é apenas uma análise de um caso concreto, com base em autores selecionados em virtude de sua relevância para o tema.

\section{Campanha de Desinformação: "Quando as Universi- dades são Condenadas, a Própria Realidade é Posta em Dúvida"}

As universidades públicas são responsáveis por grande parte da produção científica no país e têm um papel significativo na elaboração de pesquisas em todas as áreas de conhecimento. Todavia, o cenário atual não é o de valorização dessas universidades, e sim de tentativa de descrédito e desmoralização. No atual governo do presidente Jair Bolsonaro, com um viés ideológico de extrema direita e um perfil populista-nacionalista, vem ocorrendo a adoção de medidas que consolidam o desmonte de políticas educacionais, acrescido de corte e contingenciamento de recursos que, ano a ano, estrangula o funcionamento das universidades públicas brasileiras.

Sob a alegação de que as universidades públicas são ineficientes e de que elas não formam adequadamente para o mercado de trabalho, há por trás uma política neoliberal, ancorada no 
Discurso Anti-Ciência: a Desinformação como Estratégia de Ataque à Produção Científica Leonardo Luiz de Souza Rezio • Magno Luiz Medeiros da Silva

lobby das empresas particulares. A educação, no Brasil, é cada vez mais um mercado a ser disputado pelas universidades privadas. Nesta perspectiva, a política de desmonte da educação pública se intensifica (LAVAL, 2019).

Essa não é uma realidade apenas brasileira. Stanley (2020) pontua que o ataque às universidades faz parte de uma estratégia da extrema direita em todo o mundo para desqualificar o saber produzido pelas universidades e pela ciência. Sendo a universidade o local da ciência por excelência, do conhecimento e da busca pela verdade, sua desqualificação representa uma desmotivação para que as pessoas tenham seu próprio senso crítico. Ao se rejeitar o valor da ciência e dos cientistas, elimina-se qualquer exigência de debate sofisticado. Como afirma Stanley (2020, p. 48), "sem a educação não há como haver debate, restando apenas um único ponto de vista: o dominante".

Neste sentido, ressoa o discurso de que é preciso libertar as universidades dos supostos excessos liberais, uma vez que elas são costumeiramente apontadas como locais violentos e opressivos, lugares de degradação moral e de "balbúrdia". É preciso, ainda, libertá-las das ideologias "esquerdistas" e "comunistas", pois, conforme aponta Stanley (2020), o triunfo do menosprezo da expertise científica é a identificação das universidades como locais doutrinados pela esquerda e pelo "marxismo cultural", e que os acadêmicos estariam "espalhando um plano ideológico esquerdista sob disfarce de pesquisa." (STANLEY, 2020, p. 65).

Nessa campanha de desmoralização da ciência e das universidades públicas, é recorrente o uso de fake news ou desinformação, que, conforme aponta Martins (2020), seria o termo empregado para expressar a existência de conteúdos falsos, imprecisos ou manipulados que são disseminados intencionalmente. 
Discurso Anti-Ciência: a Desinformação como Estratégia de Ataque à Produção Científica Leonardo Luiz de Souza Rezio • Magno Luiz Medeiros da Silva

Diante do espetáculo da desinformação na internet e nas redes sociais, se esconde o trabalho de consultores políticos, ideólogos e cientistas especializados em Big Data, os quais Empoli (2020) os denominam de engenheiros do caos. Para esse autor, esses engenheiros do caos estão reinventando a propaganda, adaptando-a à era das selfies e das redes sociais e, como consequência, transformando a própria natureza do jogo democrático. Um dos efeitos foi o aumento do nível de ódio já presente em nossa sociedade, pois a internet abriu um mundo de oportunidades aos propagadores de ódio.

Segundo Empoli (2020), os algoritmos dos engenheiros do caos os força a sustentar uma posição interceptada nas aspirações e no medo. Assim como as redes sociais, essa nova propaganda se alimenta sobretudo das emoções negativas, pois essas são as que garantem maior participação. Daí o sucesso das fake news e das teorias da conspiração.

Empoli (2020) ilustra o papel da desinformação com um estudo do Instituto de Tecnologia de Massachusetts (MIT), publicado na revista Science, em março de 2018, o qual demonstrou que uma falsa informação tem, em média, 70\% a mais de probabilidade de ser compartilhada na internet, pois ela é, geralmente, mais original que uma notícia verdadeira. Em contrapartida, a verdade consome seis vezes mais tempo que uma fake news para atingir 1.500 pessoas. Nas redes sociais na internet, o que vale é o engajamento e pouco importa se esse engajamento é obtido pela propagação de desinformação.

As mentiras estão inseridas numa narrativa política que capta os temores e as aspirações das pessoas, enquanto os fatos que a combatem inserem-se num discurso que não é mais tido como crível. A verdade dos fatos, tomados um a um, não conta. O que 
Discurso Anti-Ciência: a Desinformação como Estratégia de Ataque à Produção Científica Leonardo Luiz de Souza Rezio • Magno Luiz Medeiros da Silva

é verdadeiro é a mensagem no seu conjunto, que corresponde a seus sentimentos e sensações. (EMPOLI, 2020).

Com isso, conforme ainda argumenta Empoli (2020), a ideia de uma esfera pública, na qual todos estão expostos às mesmas informações, com leituras de jornais e noticiários televisivos, praticamente não existe mais. Não são mais as opiniões sobre os fatos que nos dividem, mas os próprios fatos em si. Cada um está inserido dentro de sua bolha, no interior da qual algumas vozes se fazem ouvir mais do que outras e alguns fatos existem mais do que outros. Desta forma, a opinião do cientista vale tanto quanto a opinião de qualquer pessoa.

Os ataques às universidades públicas e o descrédito em relação à ciência são provocados, sobretudo, por campanhas de desinformação promovidas pelos denominados engenheiros do caos. A disseminação intencional de informações falsas na internet com o intuito de desqualificar a pesquisa científica gera, como consequência, dúvidas, medo, insegurança, culminando em radicalismo e exacerbando preconceitos.

É fácil perceber, neste momento, a concretização do fenômeno da dissonância cognitiva. Tal fenômeno foi formulado pelo psicólogo estadunidense Leon Festinger, em 1957, ao identificar que as pessoas tendem a aceitar apenas informações compatíveis com suas crenças anteriores e suas certezas ideológicas. Quanto mais uma informação é compatível com crenças e conhecimentos anteriores, mais resistentes se tornam à refutação ou correção. Esse choque entre o conhecimento antigo e o novo é a dissonância cognitiva, isto é, o desacordo entre dois conjuntos de dados igualmente obtidos por uma pessoa. O resultado desse choque é o desconforto psicológico (MARTINO, 2009). 
Discurso Anti-Ciência: a Desinformação como Estratégia de Ataque à Produção Científica Leonardo Luiz de Souza Rezio • Magno Luiz Medeiros da Silva

Conforme Festinger (1975), há dois fatores importantes que marcam a definição da dissonância cognitiva. O primeiro é que, por causar desconforto psicológico, há a necessidade de reduzir a dissonância e tentar refutá-la. O segundo, uma vez que a dissonância já se faz presente, tenta-se evitar o contato com informações dissonantes e procura-se imediatamente apoio de informações que deem respaldo ao seu ponto de vista. Encontrar pessoas que pensam e agem da mesma forma, reforça a percepção de que se está agindo corretamente.

Se uma pessoa ou fonte de informação que o indivíduo considera positivamente (ou negativamente) apoia uma opinião que o indivíduo considera negativamente (ou positivamente), irá precipitar uma tendência ou a se mudar a avaliação da opinião envolvida, ou a avaliação da fonte e, com isso, se buscar reduzir a dissonância. Quanto mais polarizada a atitude para com a fonte, mais provável que a opinião mude. Quanto mais polarizada tiver a sua própria opinião, mais provável que a fonte caia em descrédito (FESTINGER, 1975).

Além do fenômeno da dissonância cognitiva, podemos afirmar que estamos vivendo tempos de uma polarização exacerbada. A disseminação de desinformação amplia a polarização da sociedade e tem colocado à prova a própria noção de verdade. Segundo Barbosa (2019), isso traz como consequência a perda de confiança em instituições que outrora eram portadoras da verdade, como a imprensa, a ciência e as elites intelectuais em geral. Conforme diz Stanley (2020, p. 66), “quando a propaganda política consegue distorcer ideias fazendo com que se voltem contra si mesmos, quando as universidades são solapadas e condenadas como fontes de preconceito, a própria realidade é posta em dúvida." 


\section{O Mercado é o Grande Produtor da "Verdade"}

Outro fator que merece destaque na perspectiva no neoliberalismo atual é como a grade econômica se sobrepõe a outros fenômenos da vida social, que não meramente fenômenos econômicos. Ao analisar tal fato, Foucault (2008) argumenta que, a partir de meados do século XVIII, o poder político passa a adotar cada vez mais intensamente um sentido economicista. Já a partir do pós-guerra, sob a perspectiva do neoliberalismo, a busca de uma maximização de utilidade, tanto dos corpos, individualmente, quanto dos processos ligados à vida das populações, faz com que a racionalidade política passa a adquirir um sentido, ainda mais, eminentemente economicista.

Em tese de doutorado, Danner (2009) aborda este tema ao explicar como o neoliberalismo, para Foucault, é perpassado por uma regra interna de economia máxima. O indivíduo passa a ser compreendido em termos de Homo Oeconomicus, isto é, enquanto indivíduo produtivo que age e responde aos desafios que são colocados pelo mercado capitalista. Antes de tudo, esse Homo Oeconomicus precisa dar lucro, sob o princípio econômico da utilidade.

O mercado regulamenta tanto as relações sociais, quanto os comportamentos dos indivíduos em particular. Danner (2009) explica que, a partir dos fundamentos trazidos por Foucault, o mercado tornou-se o principal regulador, não só da economia, mas da sociedade como um todo. Ou seja, o fator econômico prepondera sobre qualquer outro fator, inclusive sobre o fator político e o social.

O mercado é o grande produtor da "verdade" na contemporaneidade, é ele quem dita as regras, inclusive sobre o poder público, que a ele se subordina. Neste sentido, Foucault (2008) argumenta que, no neoliberalismo, perpassado por uma regra interna 
Discurso Anti-Ciência: a Desinformação como Estratégia de Ataque à Produção Científica Leonardo Luiz de Souza Rezio • Magno Luiz Medeiros da Silva

de economia máxima, somente "um governo que respeita a especificidade da economia, será um governo que administra a sociedade civil, que administra a nação, que administra a sociedade, que administra o social" (FOUCAULT, 2008, p. 403).

Para Foucault (2008), o Homo Oeconomicus, aqui representado pelo "setor produtivo", e a sociedade civil, são dois elementos indissociáveis. A sociedade civil é o espaço concreto no interior do qual são colocados os "homens econômicos", cujo objetivo é a sua administração, neste contexto de uma radicalização da razão econômica à vida, promovida pelo neoliberalismo.

\section{"Os Estudos da UFG não têm Embasamento Científico"}

Inúmeros foram os ataques nas redes sociais direcionados tanto ao grupo de modelagem, em especial ao professor Thiago Rangel, quanto à UFG, sempre acusados de serem responsáveis por prejudicar a economia do Estado. Postagens e comentários acusativos no Twitter, Facebook e Instagram, mas sobretudo postagens feitas para serem circuladas pelo Whatsapp.

Thiago Rangel, por ter dado mais entrevistas a veículos jornalísticos, foi o rosto visível do grupo e passou a sofrer ataques pessoais. Em postagem que viralizou nas redes sociais e foi divulgada em inúmeros grupos de Whatsapp, ele foi apontado como "o responsável pelo lockdown em Goiás", "responsável pelo fechamento do comércio após três meses de omissão do Governo", chamado de "pesquisador meia boca" e "especialista" da UFG (LEWINSOHN, 2020).

Na postagem havia a fotografia do pesquisador em um fundo vermelho rodeado por beija-flores. Os beija-flores, na verdade, eram para ridicularizar sua especialidade de pesquisa, uma vez que ele estudou com modelos computacionais a diversidade 
Discurso Anti-Ciência: a Desinformação como Estratégia de Ataque à Produção Científica Leonardo Luiz de Souza Rezio • Magno Luiz Medeiros da Silva

de populações de beija-flor. Todavia, como o próprio pesquisador explica, em entrevista ao Jornal UFG (MELO e STECCA, 2020), em 30/06/2020, "as mesmas técnicas que utilizei para estudar o beija-flor, por exemplo, são também utilizadas para entender linhagens ou cepas de vírus".

Não apenas os pesquisadores foram atacados, como foi também a UFG enquanto instituição. Em artigo com autoria não identificada, publicado no site Goiás 24 horas, em 3 de agosto de 2020, a UFG foi acusada de ter "errado feio" na projeção de mortes da COVID-19 e de oferecer dados equivocados ao governo de Goiás. O texto denuncia que os professores da UFG superestimaram o volume de óbitos em $215 \%$ e anunciaram o colapso na oferta de leitos clínicos e leitos de Unidade de Terapia Intensiva (UTI), caso o índice de isolamento social continuasse abaixo dos $40 \%$, o que não ocorreu. O texto conclui que se trata de um "estudo furado", o qual "arranha a imagem da UFG" e "expõe a instituição ao descrédito", "levado o governo de Goiás a decretar o lockdown, prejudicando enormemente as atividades econômicas".

Houve ainda dois vídeos produzidos de forma institucional por associações que representam comerciários, empresários e o "setor produtivo" em geral. O primeiro vídeo foi produzido pela ACIEG (Associação Comercial, Industrial e de Serviços do Estado de Goiás), circulado nas redes sociais, sobretudo no Whatsapp. O vídeo tem um minuto e quarenta segundos de duração, mostrando imagens de Goiânia, alternando com imagens de pessoas trabalhando e fazendo diversas ações. Enquanto isso, o locutor em off denuncia que o estudo realizado pela UFG, emitido em 26 de maio de 2020, fala que o pior cenário previsto para a pandemia em Goiás, o vermelho, seria de 1.100 a 1.480 óbitos no Estado. Todavia, em 30 de junho de 2020, havia o triste, mas discrepante número de 466 óbitos, embora 
Discurso Anti-Ciência: a Desinformação como Estratégia de Ataque à Produção Científica Leonardo Luiz de Souza Rezio • Magno Luiz Medeiros da Silva

o Estado de Goiás tenha tido as menores taxas de isolamento social do país. Com isso, o vídeo aponta que a dispersão encontrada entre o estudo da UFG e a realidade foi de $235 \%$ a $316 \%$.

O vídeo mencionado aponta, ainda, que foi por causa desse estudo que foi tomada a decisão de fechamento do comércio, com base na hipótese que previa 18 mil mortos até setembro, se não houvesse um lockdown no estado. Por fim, o locutor do vídeo conclui que a realidade não condiz com os estudos previstos pela UFG, e que é preciso "analisar bem os dados e entender que essas previsões podem trazer prejuízos irreversíveis à vida, ao econômico e ao social". O vídeo termina com a assinatura da ACIEG e o slogan que aduz: "há 83 anos na defesa incondicional do empresário goiano".

O segundo vídeo circulado nas redes sociais, notadamente no Whatsapp, que também ataca a UFG e os pesquisadores em virtude da decisão pelo fechamento do comércio, trata-se da fala do presidente da Federação do Comércio do Estado de Goiás, Fecomércio-GO. No vídeo, o presidente diz que precisa fazer algumas considerações, em primeiro lugar, inicia ele dizendo que "os estudos da UFG, que estão referenciando o Governador, não têm embasamento científico".

O presidente da Fecomércio-GO, portanto, retira a responsabilidade do governador, em ter decretado o lockdown intermitente, e coloca essa responsabilidade na conta da UFG, que foi quem induziu o governador ao erro. Complementa afirmando que, colocar como risco de 18 mil pessoas morrerem em Goiás até 30 de setembro, como sugere um dos cenários do estudo, seria algo inimaginável, pois é uma média 3 vezes superior à média da Bélgica, segundo ele, a maior média de morte por milhão de habitantes do mundo. O estudo, portanto, teria levado, não apenas o governador ao erro, como também todos os prefeitos de Goiás. 
Discurso Anti-Ciência: a Desinformação como Estratégia de Ataque à Produção Científica Leonardo Luiz de Souza Rezio • Magno Luiz Medeiros da Silva

No vídeo, o presidente da Fecomércio-GO diz que a culpa das prefeituras foi a de não ter preparado leitos, medicamentos e não terem criado regras para o enfrentamento da pandemia. Ele destaca a prefeitura de Aparecida de Goiânia como o modelo a seguir, pois, de acordo com ele, tal município aumentou a oferta de novos leitos e está ofertando medicamento, além de ter criado o sistema de bandeiras. Por fim, ele defende a união das entidades privadas com o poder público (Executivo, Legislativo, Judiciário e Ministério Público), e fala que não se deve jogar trabalhadores contra empresários, esposas contra maridos ou o Ministério Público contra empresários. Da mesma forma que o vídeo da ACIEG, o vídeo da Fecomércio-GO reforça a defesa do empresariado. A novidade aqui, todavia, é a sugestão de que aumentar os leitos hospitalares e ofertar medicamentos seria a melhor solução para lidar com a pandemia, em vez de fechar o comércio, ainda que de forma intermitente.

\section{“Modelos não são Bolas de Cristal”}

Diante das críticas endereçados à UFG e aos pesquisadores do Grupo de Modelagem, acusados de terem errado e dado informações equivocadas ao Governo do Estado, a dúvida se faz pertinente. Afinal, os críticos estavam certos e o modelo utilizado na pesquisa estava, de fato, errado? Se não, por que os números apresentados na projeção foram tão discrepantes em relação aos números reais, como se verificou tempos depois.

O grupo apresentou três cenários de projeção para o futuro com base na variação do $R$, que é o número reprodutivo da doença (quantas pessoas em média são contaminadas por uma pessoa doente), medido antes da adoção de novas estratégias de isolamento, a partir do momento que a epidemia alcançou o 
Discurso Anti-Ciência: a Desinformação como Estratégia de Ataque à Produção Científica Leonardo Luiz de Souza Rezio • Magno Luiz Medeiros da Silva

"status" de transmissão comunitária em Goiás: os cenários azul, verde e vermelho.

A imprensa, bem como os críticos, se pautou, notadamente, por um dos cenários, o vermelho, e deu a ele grande visibilidade, o que projetava que poderíamos chegar a 18 mil mortes até setembro. Como explica um dos autores da pesquisa (DINIZ FILHO, 2020a), trata-se, este, de um cenário contrafactual em que não houve nenhuma medida de isolamento e a pandemia se espalhou de modo que cada pessoa infectada, durante 3 meses, contaminou mais duas novas pessoas por dia.

Os números altos projetados no cenário vermelho assustaram o governo e a sociedade, mas esse susto pode ter provocado uma reação para que não se atingissem tais números. O governo adotou 14 dias de isolamento no início de julho, após o estudo da UFG e, conforme explicam os pesquisadores, qualquer medida tomada por governos e realizada pela sociedade pode alterar o R. Outras ações foram também implementadas, como testagens em massa, rastreamento de contatos, monitoramento dos casos por telemedicina, além de protocolos específicos de higiene, distanciamento social e o uso de máscaras.

Modelos tentam capturar aspectos da realidade que são úteis para a tomada de posições. Todavia, como argumenta Diniz Filho (2020a), modelos não são "bolas de cristal", a ciência não faz "previsões". O principal objetivo dos modelos, nesse contexto da pandemia, é contrastar cenários, e ao apresentar cenários alternativos, a própria percepção destes faz com que o futuro se torne diferente.

Ao não se atingir esses números, houve a acusação de que a pesquisa estava errada, de que o modelo estava errado. Sendo assim, a pergunta correta a se fazer não seria se o modelo está certo ou errado e sim, o modelo foi útil? Neste caso, a resposta é sim! 


\section{Salvar Vidas" ou "Preservar a Economia": Afinal, quem Paga o Preço?}

Ao se afirmar que os estudos da UFG não têm embasamento científico e que os pesquisadores da instituição ofereceram dados equivocados ao governo de Goiás levando o governador ao erro, percebemos que estamos diante de uma campanha de desinformação, de forma organizada e intencional. Tal campanha teria como objetivo comprometer a reputação dos pesquisadores e da própria Universidade, para, assim, influenciar no debate e convencer a opinião pública a concordar com a reabertura do comércio em meio a pandemia, garantindo o lucro para o setor produtivo.

O descrédito em relação à modelagem da expansão da COVID-19 em Goiás, desenvolvida pelos pesquisadores da UFG, ocorreu, notadamente, pela falta de compreensão da sociedade em relação ao que significa a incerteza na ciência. Conforme observa Rangel (2020), muitos não entendem o funcionamento da ciência e acham que o conhecimento apresentado em um dado momento é "definitivo", e pode criar uma sensação de que "os cientistas não sabem".

Ao se juntar o desconhecimento da sociedade em relação às incertezas na ciência com os ataques institucionais à pesquisa desenvolvida pelo grupo de trabalho, coloca-se, assim, a sociedade contra a Universidade, contra os pesquisadores e contra a própria ciência, numa estratégia para desqualificar o saber produzido. Para isso, usam de má-fé para interpretar os números da maneira que gostariam, sem testar os dados, sem comprovação e agindo como verdadeiros engenheiros do caos.

Os vídeos produzidos pela ACIEG e pela Fecomércio-GO deixam claro que, em relação às estratégias de combate à pandemia da COVID-19, a opinião dos empresários do setor produtivo vale 
Discurso Anti-Ciência: a Desinformação como Estratégia de Ataque à Produção Científica Leonardo Luiz de Souza Rezio • Magno Luiz Medeiros da Silva

tanto quanto a opinião científica. Como bem argumenta Empoli (2020), a verdade dos fatos já não conta, o que vale é o engajamento e pouco importa se esse engajamento é obtido pela propagação de desinformação.

A estratégia dos engenheiros do caos é, exatamente, a de inflamar paixões e polarizar aos extremos, restando ao público a sensação de desestabilização, desconfiança e raiva contra aqueles que, segundo foi anunciado, foram responsáveis pela sua perda. No caso, a perda do poder econômico, ocasionado pelo fechamento parcial do comércio. Diante disso, é fácil perceber no público a ocorrência de dissonâncias cognitivas, com pessoas se entrincheirado em suas certezas ideológicas e evitando, a qualquer custo, o contato com informações dissonantes.

Conforme afirma Stanley (2020), se a sociedade é polarizada, se não há consenso e paira a incerteza, políticos demagogos e, aqui acrescentamos, empresários, podem explorar essa divisão usando a linguagem para semear o medo, acentuar o preconceito e pedir retaliação. A linguagem utilizada na notícia e nos vídeos anteriormente citados, não é usada simplesmente para transmitir informação, mas para provocar emoção. Sua função é, antes, levantar suspeitas gerais sobre a credibilidade e a decência de seus alvos, no caso a UFG, o grupo de modelagem e, em especial, o professor Thiago Rangel.

No final, as pressões políticas e econômicas para liberar o comércio se mostraram eficazes contra o isolamento social que vinha ocorrendo no início da pandemia. Aparentemente, o Governo do Estado desistiu da batalha e caiu no jogo dos empresários e do "setor produtivo". O propalado lockdown de 14 dias aberto e 14 dias fechado, por exemplo, não foi retomado. Não houve um novo decreto para fechamento do comércio, embora tenha sido claro 
Discurso Anti-Ciência: a Desinformação como Estratégia de Ataque à Produção Científica Leonardo Luiz de Souza Rezio • Magno Luiz Medeiros da Silva

que tanto a diminuição do engajamento social, quanto à adoção do isolamento ao longo do tempo culminou em um aumento do número de casos. Em 15 de junho, Goiás registrou 10 casos confirmados de COVID-19. Pouco mais de um mês depois, em 23 de julho, esse número saltou para 50 mil casos e, apenas vinte e dois dias depois, em 14 de agosto, o número dobrou para 100 mil casos confirmados no Estado (OLIVEIRA, 2020).

Nessa situação é possível perceber, portanto, as concepções de Foucault (2008) colocadas em prática, quando ele afirma que no neoliberalismo é a grade econômica que se sobrepõe a outros fenômenos da vida social, que não meramente fenômenos econômicos, como no caso, a saúde coletiva. Afinal, o Homo Oeconomicus precisa dar lucro.

Conforme bem observa Diniz Filho (2020b), o que temos visto no Brasil é uma visão "ingênua" de polos opostos entre "salvar vidas", mantendo a quarentena, ou "preservar a economia", flexibilizando as medidas de distanciamento social. Foi disseminada a crença que há uma oposição entre economia e saúde, o que é inverídico visto que ambas se estruturam de forma a promover o bem-estar coletivo e não apenas individual ou de minorias privilegiadas.

Para agradar o "setor produtivo", prefeitos e gestores passaram a dizer que seria preciso pensar em "outras formas de minimizar o problema", que não o fechamento do comércio e das atividades não essenciais como forma de se forçar o isolamento social da população. Como afirmou o presidente da Fecomércio-GO, no vídeo anteriormente descrito, o modelo a seguir é o da prefeitura de Aparecida de Goiânia, que solucionou o problema da pandemia aumentando a oferta de novos leitos e ofertando medicamentos à população.

O pesquisador Diniz Filho (2020b) denuncia essa inversão do raciocínio defendida por parte do "setor produtivo" e seguida pe- 
Discurso Anti-Ciência: a Desinformação como Estratégia de Ataque à Produção Científica Leonardo Luiz de Souza Rezio • Magno Luiz Medeiros da Silva

los gestores. Abandonar as medidas que regulamentam o distanciamento social, deixando o número de transmissões alto e dizendo que isso não é problema, pois eles foram capazes de ampliar o sistema de saúde para lidar com esse aumento, significa que estamos dispostos a pagar um preço como sociedade pelas mortes dessas pessoas. "A ideia não é ampliar a capacidade do sistema de saúde para atender ao máximo de infectados que adoeçam, para poder liberar atividades comerciais, e sim reduzir o número de infectados!" (DINIZ FILHO, 2020b).

Diante disso, Diniz Filho (2020b) ainda nos deixa com a seguinte pergunta: quem realmente paga o preço? É fácil para o "setor produtivo" dizer que temos que "priorizar" a economia e "comemorar a retomada", quando quem paga o preço são os pobres e as pessoas que não conseguem se proteger. Os estudos de prevalência mostram que a COVID-19 avança mais rapidamente entre os mais pobres, justamente os que não têm acesso a um serviço de saúde de qualidade, que precisam ir para trabalho pegando ônibus lotado, e tendo que acreditar que vai ficar tudo bem com ele(a) e com sua família.

\section{Conclusão}

Diante dessa discussão que tomou conta dos debates nos últimos meses entre "salvar vidas" ou "preservar a economia", no meio de uma pandemia, é a população que se encontra desamparada, dividida entre a ciência e o poder econômico. Afinal, a ciência, como ficou mostrado, não tem respostas para tudo e precisa de tempo para se desenvolver uma análise mais precisa da situação. Tempo é o que o setor produtivo não está disposto a aguardar, pois quanto mais tempo se espera, mais se deixa de lucrar. 
Discurso Anti-Ciência: a Desinformação como Estratégia de Ataque à Produção Científica Leonardo Luiz de Souza Rezio • Magno Luiz Medeiros da Silva

O grupo de modelagem da expansão espaço-temporal da COVID-19 em Goiás, da UFG, fez o trabalho que se esperava da ciência: alertar o poder público para os riscos da pandemia, e traçar os cenários possíveis, incluindo aquele que não se tivesse sido tomada nenhuma medida de isolamento social. Como se percebeu, isso não aconteceu, porque a população foi alertada e medidas foram tomadas.

Frente à batalha que se estabeleceu diante da opinião pública, entre a ciência, de um lado, e o "setor produtivo", de outro, este último parece ter tido mais força para sobrepor a sua narrativa. Mas não o fez baseado nos fatos e na razão, e sim no medo. O medo do desemprego, da queda de renda, do caos econômico, não importa se a situação anterior era de caos sanitário. Para isso, não hesitou em usar de estratégias de desinformação e não se preocupou em checar os fatos, em verificar no que consistia a pesquisa. O engajamento que pretendiam se realizou, mas levantando dúvidas sobre a pesquisa e atacando a Universidade e os cientistas.

$\mathrm{O}$ artigo procurou compreender, a partir deste caso, como a ciência, as universidades e os cientistas puderam ser tão facilmente desacreditados e atacados, a partir do momento em que se colocaram contra os interesses imediatos do "setor produtivo", ainda que estivéssemos vivendo uma situação excepcional de pandemia e houvesse interesses maiores envolvidos, no caso, a saúde pública.

\section{Referências}

Barbosa, Mariana in: Barbosa, Mariana (Org). Pós-Verdade de Fake News: reflexões sobre a guerra de narrativas. Rio de Janeiro: Cobogó, 2019.

DANNER, Fernando. Biopolítica e liberalismo: a crítica da racionalidade política em Michel Foucault. 2011. 168 f. Tese (Doutorado em Filosofia) 
Discurso Anti-Ciência: a Desinformação como Estratégia de Ataque à Produção Científica Leonardo Luiz de Souza Rezio • Magno Luiz Medeiros da Silva

- Pontifícia Universidade Católica do Rio Grande do Sul, Porto Alegre, 2011.

DiniZ FilHO, José Alexandre Felizzola. Todos os modelos estão errados, MAS ALGUNS SÃo ÚteIS... E QUe bOM QUe SEJA ASSIM!. CIÊNCIA, UnIVERSIDADE E OUTRAS IDEIAS, 2020A. DISPONIVEL EM: HTTPS://WWW.BLOGALEXDINIZ.COM/POST/ TODOS-OS-MODELOS-ESTÃO-ERRADOS-MAS-ALGUNS-SÃO-ÚTEIS-E-QUE-BOM-QUE-SEJA-ASSIM. ACESSO EM: 30 AgO. 2020.

Que a curva se cumpra... CiênCia, Universidade e outras ideias, 2020B. DisPonÍVEL EM: HTTPS://WWW.BLogALEXDINIZ.COM/POST/QUE-A-CURVA-SE-CUMPRA. Acesso em: 30 ago. 2020.

EMPOli, Giuliano Da. Os engenheiros do caos. São Paulo: Vestígio, 2020.

FESTINGER, Leon. Teoria da dissonância cognitiva. Trad. Eduardo Almel23 DA. Rio de JANeIRO: Zahar Ed., 1975.

FoucAUlt, Michel. Nascimento da Biopolítica. Curso no Collège de France (1978-1979). São Paulo: Martins Fontes, 2008.

LAVAL, Christian. A escola não é uma empresa: o neoliberalismo em ataque AO ENSINO PÚBLICO. BOITEMPO EDITORIAL, 2019.

LEWINSOHN, Thomas. Difamação, negacionismo e a volta do Dirceu BorBOLETA. O ECO, 2020. DisPoníVEL EM: WWW.OeCO.ORG.BR/COLUNAS/COLUNISTAS-CONVIDADOS/DIFAMACAO-NEGACIONISMO-E-A-VOLTA-DO-DIRCEU-BORBOLETA. ACESSO EM: 12 AGO. 2020.

LONGO, Malu. Professor da UFG alvo de ataques nas redes diz que não Impôs Isolamento em Goiás. O Popular, GoiÂnia, 30/06/20. Disponível em: HTTPS://WWW.OPOPULAR.COM.BR/NOTICIAS/CIDADES/PROFESSOR-DA-UFG-ALVO-DE-ATAQUES-NAS-REDES-DIZ-QUE-N\%C3\%A3O-IMP\%C3\%B4S-ISOLAMENTO-EM-GOI\%C3\%A1s-1.2077782. AcEsSO EM: 12 ago. 2020. 
Discurso Anti-Ciência: a Desinformação como Estratégia de Ataque à Produção Científica Leonardo Luiz de Souza Rezio • Magno Luiz Medeiros da Silva

martino, luís Mauro Sá. Teoria da Comunicação: ideias, conceitos e métodos. Petrópolis, RJ: Vozes, 2009.

MARTinS, Helena in: MARTinS, Helena (org.). Desinformação: crise política e Saídas democráticas para as fake news. São Paulo: Veneta, 2020.

MElo, Carolina e SteCCA, Kharen. Conheça os pesquisadores da UFG do Grupo de Modelagem. Jornal UFG, GoiÂnia, 30/06/20. Disponível em: HTTPS://JORNAL.UFG.BR/N/130280-CONHECA-OS-PESQUISADORES-DA-UFG-DO-GRUpo-de-modelagem. Acesso em: 11 ago. 2020.

Projeções da UFG acertam dados reais da PANDemia em Golás. JorNAL UFG, GoIÂNIA, 11/08/20. DISPONÍVEL EM: JORNAL.UFG.BR/N/131742-PROJECOES-DA-UFG-ACERTAM-DADOS-REAIS-DA-PANDEMIA-EM-GOIAS. ACESSO EM: 11 AGO. 2020.

OLIVEIRA, Rafael. Goiás ULtrapassa 100 mil casos de coronavírus com 24 O DESAFIO DE EQUILIBRAR A RETOMADA ECONÔMICA E O ISOLAMENTO SOCIAL. G1 GoIÁs, GOIÂNIA, 14/08/20. DISPONÍVEL EM: HTTPS://G1.GLOBO.COM/GO/GOIAS/ NOTICIA/2020/08/14/GOIAS-ULTRAPASSA-100-MIL-CASOS-DE-CORONAVIRUS-COM-O-DESAFIO-DE-EQUILIBRAR-A-RETOMADA-ECONOMICA-E-O-ISOLAMENTO-SOCIAL. GHtMl. Acesso em: 30 ago. 2020.

RANGEL, Thiago F. A Pandemia de COVID-19: A CIÊNCIA FEITA E APLICADA em tempo-real [Webinário]. Youtube IQ-UFG. Disponível em: wwW.youtube. cOM/WATCh?v=JMDdEBF7Psc. Acesso em: 14 Ago. 2020.

RODRIGUES, GUILHERME. Novo estudo da UFG estima colapso hospitaLAR EM JULho E 18 MIL MORTeS POR Covid-19 até SETEMBro, em Goiás. G1 GolÁs, GoIÂNIA, 29/06/20, DisPONÍVEL EM: G1.GLOBO.COM/Go/GOIAS/NOTICIA/2020/06/29/NOVO-ESTUDO-DA-UFG-ESTIMA-COLAPSO-HOSPITALAR-EM-JULHO-E-18-MIL-MORTES-POR-COVID-19-ATE-SETEMBRo-eM-GOIAS.GHTML. ACESSO EM: 30 AGO. 2020.

STANLEY, Jason. Como funciona do fascismo: a política do "nós" e "eles". Trad. Bruno Alexander. Porto Alegre: L\&PM, 2020. 
Discurso Anti-Ciência: a Desinformação como Estratégia de Ataque à Produção Científica Leonardo Luiz de Souza Rezio • Magno Luiz Medeiros da Silva

UFG ERROU FEIO NA PROJEÇÃO DE MORTES DA COVID-19 E OFERECEU DADOS EQUIvocados ao governo de Goiás. Golás 24 horas. Golânia, 03/08/20. DisPONIVEL EM: GOIAS24HORAS.COM.BR/154595-UFG-ERROU-FEIO-NA-PROJECAO-DE-MORTES-DA-COVID-19-E-OFERECEU-DADOS-EQUIVOCADOS-AO-GOVERNO-DE-GOIAS. ACESSO EM: 12 AGO. 2020.

\section{5}

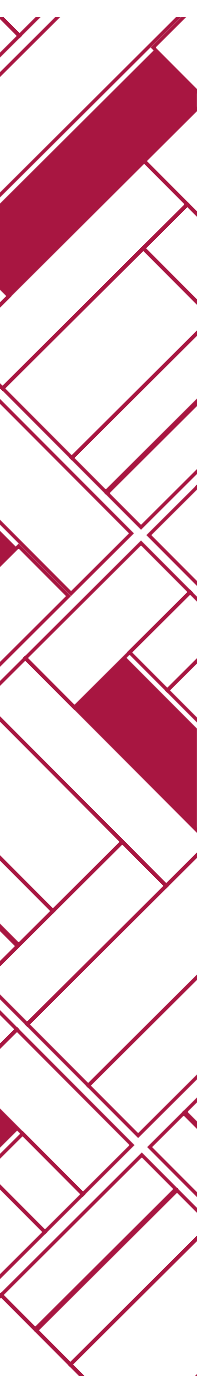


Discurso Anti-Ciência: a Desinformação como Estratégia de Ataque à Produção Científica Leonardo Luiz de Souza Rezio • Magno Luiz Medeiros da Silva

26

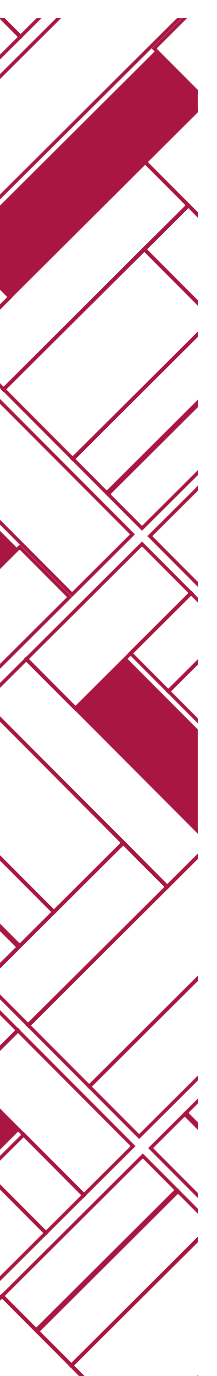

